\title{
FAMÍLIA CANZIANI: CARTÓRIO E CONGRESSO
}

\author{
Flávia Cruz ${ }^{1}$ \\ Luciano De Marchi Mello
}

\begin{abstract}
Resumo: Com o objetivo de evidenciar a dinâmica entre relações de poder e parentesco, marcada pela ambiguidade entre a esfera pública e privada, este artigo reconstitui a trajetória política e genealógica da família Canziani, do ex-deputado federal Alex Canziani, desde a migração da família à cidade de Londrina, Paraná, em 1935, à rápida fundação do cartório de imóveis ainda sob propriedade da família. Após cinco legislaturas consecutivas na Câmara Federal, Alex foi sucedido por sua filha, Luísa Canziani, a mais jovem parlamentar da atual legislatura.
\end{abstract}

Palavras-chave: Alex Canziani; Luísa Canziani; Cartório; Família; Genealogia

\section{CANZIANI FAMILY: REGISTRY OFFICE AND CONGRESS}

\begin{abstract}
With the aim of highlighting the dynamics between power relations and kinship, marked by ambiguity between the public and private spheres, this article reconstructs the political and genealogical trajectory of the Canziani family, of the former federal deputy Alex Canziani, from the migration of the family to the city of Londrina, Paraná, in 1935, to the rapid foundation of the real estate registry office still under family ownership. After five consecutive legislatures in the Federal Chamber, Alex was succeeded by his daughter, Luísa Canziani, the youngest parliamentarian of the current legislature.
\end{abstract}

Keywords: Alex Canziani; Luísa Canziani; Registry office; Family; Genealogy

\section{Introdução}

Poder político e relações de parentesco são elementos indissociáveis se objetivamos compreender, de maneira ampla, nossa complexa estrutura político-social. Independente dos valores republicanos, que idealizam a separação entre o público e o privado, empiricamente, ambas as esferas encontram-se associadas e operando, transitoriamente, entre Estado e vida íntima.

A abrangência desta relação também possui capilaridade, não se resumindo à regiões específicas ou cargos de maior visibilidade. Também não é possível isolá-la

\footnotetext{
${ }^{1}$ Graduanda de Comunicação Organizacional pela UTFPR - Universidade Tecnológica Federal do Paraná. E-mail: flaviacam21@gmail.com

2 Graduando de Comunicação Organizacional pela UTFPR - Universidade Tecnológica Federal do Paraná. E-mail: lucianodmm@gmail.com
} 
historicamente, já que uma de suas características é a adaptação, ocupando, atualmente "instituições modernas, complexas e racionais" (GOULART et al, 2017, p. 4).

A disputa eleitoral, no âmbito municipal, estadual e federal, desta forma, se converte em instrumento de perpetuação política e hereditariamente. Afinal, não são poucos os exemplos de famílias que ocuparam e ocupam cargos no legislativo ou executivo, por consecutivas gerações. Mesmo no judiciário e em outras instituições públicas de ingresso profissional mediante concurso público, onde se deposita maior confiança no mérito individual, não é incomum o reconhecimento de membros pertencentes ao mesmo núcleo familiar. Como indicam Goulart et al (2017, p.1):

Famílias e determinados sobrenomes estão cada vez mais presentes no espaço político, seja na ocupação de cargos eletivos nas diversas esferas de poder, como também em funções de nomeação, na burocracia estatal. Famílias históricas atuam em todas as instituições sociais e políticas de maneira decisiva, sendo um retrato que, de forma recorrente, sempre indicou historicamente uma manifestação social arcaica de regiões específicas do Brasil.

Essa relação pode ser observada não só pela ocupação de cargos eletivos e de ingresso por concurso, mas também em cargos da burocracia estatal e postos estratégicos (GOULART et al, 2017, p.3):

Em quase todas as regiões e estados, mesmos os considerados mais centrais ou desenvolvidos situados no Centro-Sul, ao longo do século XX e início do XXI, tem-se apresentado este padrão de atuação, em que famílias controlam e atuam nos principais e estratégicos postos do aparelho de Estado.

Dentre os postos relevantes, destacamos os cartórios, instituições fundamentais à garantia de direitos, à cidadania e ao registro histórico, em uma complexa relação entre os limites do público e do privado.

Dessa forma, analisaremos a biografia política da família Canziani, do exdeputado federal pelo Partido Trabalhista Brasileiro (PTB), Alex Canziani, como exemplo de como as relações familiares e de parentesco estão presentes no poder público e estatal. Apresentaremos sua trajetória desde o cartório que sempre esteve em propriedade da família, o ingresso na vida política, as cinco legislaturas como deputado federal consecutivas e a eleição de sua filha, Luísa Canziani, à Câmara Federal. 
Família Canziani: biografia, trajetória política e parentesco

Alex Canziani Silveira, ou apenas Alex Canziani, nome que adotou politicamente o membro com maior reconhecimento em âmbito nacional da família, nasceu em 11 de junho de 1964, em Londrina, no Paraná. Cursou Direito na Universidade Estadual de Londrina (UEL) de 1985 a 1990, onde foi presidente do centro acadêmico de 1987 a 1988 (ALEX, 2019). Antes de ingressar na vida política, de acordo com a sua biografia publicada no site da Câmara dos Deputados (2019), Canziani foi escriturário, assunto que abordaremos mais adiante.

Segundo o verbete biográfico de Alex Canziani (CÂMARA DOS DEPUTADOS, 2019a), em 1989, antes mesmo de terminar a graduação, Canziani se elege para seu primeiro cargo público como vereador de Londrina, no Paraná, pelo Partido Trabalhista Brasileiro (PTB), sendo reeleito também para o período seguinte, de 1993 a 1996, quando foi presidente da Câmara Municipal. Ainda em 1992, se torna presidente do diretório municipal do PTB. Foi também presidente da Associação dos Vereadores do Médio Paranapanema (Avempar) de 1993 a 1999 e presidente da Companhia de Desenvolvimento de Londrina (Codel) de 1997 a 1998. Canziani tem sua primeira experiência no executivo em 1997, depois de eleito, em 1996, vice-prefeito de Londrina na chapa de Antônio Casemiro Belinati.

Em 1998, Canziani deixa seu cargo de vice-prefeito para concorrer à Câmara Federal, sendo eleito com 74.876 votos. Em 1999, de 3 fevereiro a 22 de setembro, convidado pelo então governador do Paraná, Jaime Lerner, pede licença na Câmara para ocupar o cargo de secretário de Empregos e Relações de Trabalho. De volta ao Congresso, ainda em 1999, deixa o PTB e se filia, por pouco tempo, ao Partido da Frente Liberal (PFL), migrando, logo em seguida, para o Partido da Social Democracia Brasileira (PSDB). Ocupa, ainda nesta primeira legislatura, os cargos de presidente da Subcomissão de Turismo da Câmara dos Deputados, vice-líder da bancada do PSDB e vice-líder do bloco PSDB/PTB.

Reeleito deputado federal em 2002, com 76.195 votos, assume o cargo de presidente da Frente Parlamentar em Defesa do Turismo e da Frente Parlamentar em Defesa do Ensino Profissional, também integrando a Comissão Mista de Planos, 
Orçamentos Públicos e Fiscalização do Congresso Nacional.

Retorna ao PTB em 2003 e em 2004 candidata-se à prefeitura de Londrina. Com 5.081 votos, termina o pleito em sexto e, consequentemente, não vai ao segundo turno. Em 2005, assume a presidência estadual do PTB. Em 2006, Canziani é indiciado por crime contra a administração pública e peculato, por supostamente ter utilizado dinheiro público na compra de marmitex durante a campanha eleitoral de 1998, sendo, posteriormente, inocentado e o caso arquivado. Ainda em 2006, é eleito deputado federal pela terceira vez, com 111.472 votos, ocupando a presidência da Subcomissão Especial de Educação Profissional, Educação à Distância e Novas Tecnologias Educacionais e da Frente Parlamentar de Educação Profissional, Tecnológica, Educação à Distância e Novas Tecnologias Educacionais do Congresso Nacional, participando ainda da Comissão de Turismo e Desporto, Comissão de Educação e Cultura, Comissão de Legislação Participativa e Comissão de Segurança Pública e Combate ao Crime Organizado. Também foi coordenador da bancada do Paraná no Congresso, em 2009 e 2010.

Em 2010 é reeleito deputado federal pela quarta vez consecutiva, com 149.693 votos (JUSTIÇA ELEITORAL, 2010), participando da Comissão de Educação e a Comissão de Cultura. Reeleito pela quinta vez em 2014 com 187.475 votos (JUSTIÇA ELEITORAL, 2014), ocupa as mesmas comissões da legislatura anterior e se torna vicelíder do bloco PTB, PROS, PSL, PRB e vice-líder do bloco PTB/PROS (CÂMARA DOS DEPUTADOS, 2019a).

Após cinco legislaturas como deputado federal, Alex Canziani candidata-se ao Senado pela primeira vez em 2018 (SENADO FEDERAL, 2018), indicando sua filha, Luísa dos Santos Silveira, que utiliza o sobrenome político do pai, para a disputa à Câmara (RUMO, 2018). Com 1,3 milhões de votos, Alex acaba derrotado por Oriovisto Guimarães (Podemos) e Flávio Arns (Rede) (JUSTIÇA ELEITORAL, 2018), mas consegue eleger sua filha, que, com 22 anos, é hoje a deputada mais jovem do país (GELAPE; PAIXÃO, 2018).

De acordo com dados coletados no jornal Folha de Londrina (2008), os avós maternos de Alex Canziani, Severo de Rudim Canziani e Jurema Neves Canziani migraram para Londrina em maio de 1935. Severo, primeiro Coletor do Estado a ser 
nomeado na cidade, se dedicou à atividade cartorária ao instalar, em 1941, o Cartório do $2^{\circ}$ Ofício de Registro de Imóveis de Londrina (TITULARES, 2005). Jurema era professora normalista e também trabalhava no cartório do marido. Do casamento, nasce Severo de Rudim Canziani Filho e Vera Maria Canziani Silveira (MORRE, 2008). Vera, por sua vez, se casa com Ody Silveira, respectivamente, mãe e pai de Alex Canziani. Ody, posteriormente, se tornou um tradicional médico na cidade. Alex possui mais três irmãos, Ody Silveira Junior, médico cirurgião plástico, Vanessa Canziani Silveira Teles, arquiteta, e Ivan Canziani Silveira, advogado (OSWALDO, 2017). Alex casou-se com Ana Lúcia Arruda dos Santos Silveira, advogada que atua na área de direito imobiliário, também graduada pela UEL, conforme informado em sua página pessoal no site Linkedin (2019). Com ela, teve dois filhos: Luísa dos Santos Silveira, advogada, e Alex Canziani dos Santos Silveira, de 17 anos (EXCESSO, 2013).

Luísa, como informamos, foi eleita deputada federal pelo PTB em 2018, com apenas 22 anos, antes mesmo de concluir a graduação em direito pela UEL (DEPUTADA, 2018). Além do sobrenome não presente em sua certidão de nascimento, desde a campanha Luísa seguiu os passos do pai, defendendo pautas relacionadas à educação, com caráter técnico e profissionalizante (SAIBA, 2018). Em 2019, na atual legislatura, Luísa integra a Comissão de Educação e é presidente da Comissão de Defesa dos Direitos da Mulher (CÂMARA DOS DEPUTADOS, 2019b).

\section{Cartórios e imóveis}

Conforme apontado anteriormente, o Cartório do $2^{\circ}$ Ofício de Registro de Imóveis de Londrina, localizado no Edifício Metrópolis, Avenida Paraná, número 427, foi instalado em 1941, por Severo de Rudim Canziani, avô do ex-deputado, e sempre pertenceu a família. Alex Canziani ocupou o cargo de Oficial Registrador de Imóveis no cartório, de 1984 a 1997, segundo sua biografia publicada no site da Câmara, período que coincide com a época em que foi vereador e vice-prefeito em Londrina (CÂMARA DOS DEPUTADOS, 2019a).

Há registros (CLASSIFICADOS, 2018) de que, além do próprio Alex, seus 
irmãos, Vanessa e Ivan, também ocuparam atividades profissionais no cartório, como escreventes substitutos. Após a saída de Alex, sua mãe, Vera Maria Canziani Silveira, assume o cargo de Oficial Registrador de Imóveis.

Segundo dados do Tribunal Superior Eleitoral (TSE) de 2018, seu patrimônio em bens declarados é de $\mathrm{R} \$ 2.401 .824,81$. É notável que boa parte do patrimônio da família está concentrado em empresas do setor imobiliário, como o grupo Botucarai Administradora de Imóveis SS Ltda (CNPJ: 05.273.277/0001-01) (BOTUCARAÍ, 2019), no qual fazem parte sua mãe, Vera Maria Canziani Silveira, seus irmãos, Ody Silveira Junior e Ivan Canziani Silveira, e próprio Alex, que atua na área de corretagem no aluguel de imóveis e possui capital social de $\mathrm{R} \$ 1.408 .526,00$; Inspirar Participações e Investimentos Ltda (CNPJ: 30.55.867/0001-35) (INSPIRAR, 2019), pertencente a ele, sua esposa, Ana Lúcia Arruda dos Santos Silveira, e seu filho, ainda menor de idade, que atua na área de aluguel de imóveis próprios e possui capital social de R\$182.000,00); Nova Prado Empreendimentos Imobiliários Spe Ltda (CNPJ: 31.001.036/0001-13) (NOVA, 2019), também pertencente à Ana Lúcia, que atua na área de obras de engenharia civil e possui capital social de $\mathrm{R} \$ 543.000,00$; Tulipas Incorporação e Administração Ltda (CNPJ: 20.323.456/0001-08) (TULIPAS, 2019), grupo empresarial no qual faz parte sua irmã, Vanessa Canziani Silveira Teles, que atua na área de incorporação de empreendimentos imobiliários e possui capital social de R\$303.562,79; Canziani Silveira Empreendimentos e Participações Ltda (CNPJ: 26.881.969/0001-02) (CANZIANI, 2019), grupo empresarial no qual também faz parte Vanessa Canziani Silveira Teles, que atua na área de aluguel de imóveis próprios e tem capital social de R $\$ 2.982 .922,00 ;$ FTCM Empreendimentos e Participações Ltda (CNPJ: 28.240.830/0001-05) (FTCM, 2019), outra propriedade de sua de Vanessa, que atua na área de aluguel de imóveis próprios e tem capital social de $\mathrm{R} \$ 913.308,00$; Ivan Canziani Silveira - Administração de Imóveis Próprios Ltda - Eireli (CNPJ: 27.336.412/0001-53) (IVAN, 2019), pertencente ao seu irmão, Ivan Canziani Silveira, que atua na área de aluguel de imóveis próprios e tem capital social de $\mathrm{R} \$ 600.000,00$.

A titularidade das serventias extrajudiciais, como são chamados constitucionalmente os cartórios, por força de lei, precisam ser outorgadas mediante concurso público há mais de um século, como informa Machado (2015, p.16): 
A exigência na questão da necessidade da prestação de concurso para assumir a titularidade dos cartórios não é nova. Conforme afirmação da Andecc, a obrigatoriedade teria sido estabelecida pela primeira vez no Brasil através do Decreto 3.322 do ano de 1887, editado na época pela Princesa Isabel.

O assunto foi apreciado de maneira mais consistente na Constituição de 1988, mais especificamente no artigo 236, regulamentado em 1994 pela lei 8.935. Em 2009, após o Conselho Nacional de Justiça (CNJ) editar duas resoluções pela obrigatoriedade dos concursos, retoma-se a discussão sobre a PEC471, apresentada em 2005 pelo então deputado João Campos de Araújo (PSDB). A "PEC dos Cartórios", como fícou popularmente conhecida, visava alterar o parágrafo $3^{\circ}$ do artigo 236 da Constituição Federal, ampliando as possibilidades de titulação. Sobre o episódio, Machado (2015, p.16) escreve:

Tais medidas fariam com que fosse organizado um lobby de tabeliães interinos, objetivando a aprovação da PEC dos Cartórios no Congresso. Um dos defensores de tal medida foi o Deputado Federal eleito pelo PTB/PR Partido Trabalhista Brasileiro, sede Paraná - (gestões 1999-2003, 2003-2007, 2007-2011) Alex Canziani Silveira

Evidencia-se, deste modo, como as relações de poder são utilizadas para a aparente perpetuação das relações de parentesco nos postos de titularidade dos cartórios do Brasil. No caso aqui analisado, podemos observar, inclusive, duas perspectivas simultâneas sobre a questão. Por um lado, o cartório que sempre esteve em propriedade da família, com a titularidade sendo transferida hereditariamente. Por outro, a perpetuação no poder político familiar, que se inicia em Alex Canziani e, cinco legislaturas depois, se conserva em sua filha, Luísa Canziani.

\section{Considerações}

Ao estudarmos a trajetória do ex-deputado Alex Canziani, buscamos identificar as conexões entre núcleo familiar e o aparelho do Estado. Verificamos, durante o processo, que a ascensão da carreira política possui uma forte conexão com as estruturas de parentesco. A transferência do capital político de pai para filha, já que, mesmo muito 
jovem, Luísa Canziani foi eleita em seu primeiro pleito, evidencia essa relação. Luísa também foi indicada a assumir cargos de liderança nas comissões da PEC015/15, sobre o FUNDEB, e participa da Comissão Externa do Ministério da Educação e da Comissão de Defesa dos Direitos da Mulher (CÂMARA DOS DEPUTADOS, 2019b). Assim, podemos salientar que Luísa, ainda em início de carreira política, está inserida nas mesmas frentes que eram encabeçadas pelo pai enquanto parlamentar. Observamos também a intrínseca relação entre parentesco e poder, no desenvolvimento de capital político e econômico, por meio de redes familiares, em concomitância à propriedade de cartórios.

\section{Referências}

ALEX Canziani. CPDOC-FGV. Verbete Alex Canziani. Disponível em: $\langle$ http://www.fgv.br/cpdoc/acervo/dicionarios/verbete-biografico/canziani-alex >. Acesso em: 01 maio 2019.

ANA LÚCIA ARRUDA DOS SANTOS SILVEIRA. Linkedin. Disponível em: $<$ https://www.linkedin.com/in/ana-1\%C3\%BAcia-arruda-dos-santos-silveira34744a63/?originalSubdomain=br $>$. Acesso em: 01 maio 2019.

BOTUCARAI Administradora de Imóveis Ss Ltda. Disponível em: $<$ https://www.cnpjconsultas.com/empresa/botucarai-administradora-de-imoveis-ssltda/05273277000101>. Acesso em: 01 maio 2019.

CÂMARA DOS DEPUTADOS. Alex Canziani. Disponível em: <https://www.camara.leg.br/deputados/73458/biografia>. Acesso em: 01 maio 2019a.

CÂMARA DOS DEPUTADOS. Luísa Canziani. Disponível em: <https://www.camara.leg.br/deputados/204410/biografia>. Acesso em: 01 maio 2019b.

CANZIANI Silveira Empreendimentos e Participacoes Ltda. Disponível em: $<$ https://www.cnpjconsultas.com/empresa/canziani-silveira-empreendimentos-eparticipacoes-1tda/26881969000102 >. Acesso em: 01 maio 2019. 
CLASSIFICADOS. Folha de Londrina. Londrina. 22 dez. 2018. Disponível em: $<$ http://www.controlemunicipal.com.br/site/geral/licitacao/download.php?arquivo=0801 19131748 24publicacao_de_de_retificacao_pdf.pdf\&cliente=86> $>$. Acesso em: 01 maio 2019.

EXCESSO de esporte pode causar lesões. Folha de Londrina. Londrina. 23 dez. 2013. Disponível em: <https://www.folhadelondrina.com.br/saude/excesso-de-esporte-podecausar-lesoes-866494html >. Acesso em: 01 maio 2019.

FTCM Empreendimentos e Participacoes Ltda. Disponível em: <https://www.cnpjconsultas.com/empresa/ivan-canziani-silveira-administracao-deimoveis-proprios-eireli/27336412000153 > . Acesso em: 01 maio 2019.

GELAPE, Lucas; PAIXÃO, André. Veja quem são os deputados mais novos e mais velhos eleitos em 2018. G1. 8 de out. 2018. Eleições 2018. Disponível em: <https://g1.globo.com/politica/eleicoes/2018/eleicao-emnumeros/noticia/2018/10/08/veja-quem-sao-os-deputados-mais-novos-e-mais-velhoseleitos-em-2018.ghtml>. Acesso em: 01 maio 2019.

GOULART, Mônica H. H. S; OLIVEIRA, Ricardo C. de ; MONTEIRO, José M.; VANALI, A. C. Família, parentesco, instituições e poder no Brasil: retomada e atualização de uma agenda de pesquisa. Revista Brasileira de Sociologia, v. 5, n. 11, 2017.

INSPIRAR Participacoes e Investimentos Ltda. Disponível em: <https://www.cnpjconsultas.com/empresa/inspirar-participacoes-e-investimentos-

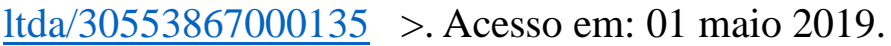

IVAN Canziani Silveira - Administracao de Imoveis Proprios - Eireli. Disponível em: <https://www.cnpjconsultas.com/empresa/ivan-canziani-silveira-administracao-deimoveis-proprios-eireli/27336412000153 > . Acesso em: 01 maio 2019.

JUSTIÇA ELEITORAL. TRE PR: eleições 2010 - resultados $1^{\circ}$ turno. Disponível em: <http://www.justicaeleitoral.jus.br/arquivos/tre-pr-eleicoes-2010-resultados-1o-turno>. Acesso em: 01 maio 2019.

JUSTIÇA ELEITORAL. TRE PR: eleições 2014 - resultados $1^{\circ}$ turno. Disponível em: <http://www.justicaeleitoral.jus.br/arquivos/tre-pr-eleicoes-2014-resultados-1o-turno>. Acesso em: 01 maio 2019.

JUSTIÇA ELEITORAL TRE PR: eleições 2018 - resultados $1^{\circ}$ turno. Disponível em: $<$ https://apps.tre-pr.jus.br/files/noticias/tre-pr-resultados-eleicoes-2018-1-turno.zip >. Acesso em: 01 maio 2019. 
MORRE a pioneira jurema canziani. Folha de Londrina. Londrina. 22 abr. 2008. Disponível em: <https://www.folhadelondrina.com.br/cidades/morre-a-pioneira-juremacanziani-638852.html >. Acesso em: 01 maio 2018.

MACHADO, V. Do berço Ao túmulo: Família e Cartórios no Paraná. Tese de Doutorado (Sociologia). Universidade Federal do Paraná, 2015.

NOVA Prado Empreendimentos Imobiliarios Spe Ltda. Disponível em: <https://www.cnpjconsultas.com/empresa/nova-prado-empreendimentos-imobiliariosspe-ltda/31001036000113 >. Acesso em: 01 maio 2019.

OSWALDO Militão. Folha de Londrina. Londrina. 18 de ago. 2017. Disponível em: <https://www.folhadelondrina.com.br/folha-gente/oswaldo-militao-985399.html>.

Acesso em: 01 maio 2019.

RUMO à eleição: a filha de Canziani, a briga dos irmãos Dias. Gazeta do Povo. Curitiba. 24 abr. 2018. Disponível em: <https://www.gazetadopovo.com.br/vozes/caixazero/rumo-eleicao-filha-de-canziani-briga-dos-irmaos-dias/> . Acesso em: 01 maio 2019.

SAIBA quem são e o que querem os mais jovens deputados federais. O Globo. 15 out. 2018. Disponível em: <https://oglobo.globo.com/brasil/saiba-quem-sao-o-que-queremos-mais-jovens-deputados-federais-23155467>. Acesso em: 01 maio 2019.

SENADO FEDERAL. Conheça os candidatos ao senado pelo paraná. 2 de out. 2018. Senado Notícias. Disponível em: <https://www12.senado.leg.br/noticias/materias/2018/10/02/conheca-os- candidatos-aosenado-pelo-parana>. Acesso em: 01 maio 2019.

TITULARES defendem seus ofícios. Folha de Londrina. Londrina. 16 abr. 2005. Disponível em: <https://www.folhadelondrina.com.br/cadernos-especiais/titularesdefendem-seus-oficios-525953.html> . Acesso em: 01 maio 2019.

TULIPAS - Incorporacao e Administracao Ltda. Disponível em: <https://www.cnpjconsultas.com/empresa/tulipas-incorporacao-e-administracaoltda/20323456000108>. Acesso em: 01 maio 2019.

TRIBUNAL SUPERIOR ELEITORAL. Divulgação de candidaturas e contas eleitorais. Disponível em: $\quad$ http://www.tse.jus.br/eleicoes/eleicoes2018/divulgacandcontas\#/candidato/2018/ >. Acesso em: 5 maio 2019. 2022802018/PR/160000622846/bens >. Acesso em: 01/05/2019.

Recebido em: 30 maio 2019.

Aceito em: 24 jun. 2019. 